\title{
Diagnosing respiratory syncytial virus by nasal lavage
}

\author{
I M Balfour-Lynn, D R Girdhar, C Aitken
}

\begin{abstract}
Nasal lavage was compared with nasopharyngeal aspiration for diagnosis of respiratory syncytial virus infection. Nasal lavage and nasopharyngeal aspiration were performed on 50 occasions in 32 infants (median age 5.6 months) with acute viral wheezing. Compared with nasopharyngeal aspiration, nasal lavage had a positive predictive value of $95.6 \%$ and negative predictive value of $92 \cdot 5 \%$. These comparable results and lack of adverse effects make nasal lavage the preferred method.

(Arch Dis Child 1995; 72: 58-59)
\end{abstract}

Keywords: nasal lavage, nasopharyngeal aspiration, respiratory syncytial virus.

Diagnosis of respiratory syncytial virus (RSV) infection is important for clinical management, as well as epidemiology and research. The current gold standard in clinical practice is to use direct immunofluorescence to detect RSV antigen on exfoliated respiratory epithelial cells recovered by nasopharyngeal aspiration. However, nasopharyngeal aspiration is not always successful, with inadequate samples sometimes collected. Furthermore, it may be associated with local trauma as well as coughing spasms, vagal bradycardia, and transient hypoxaemia.

Other methods of collecting infected respiratory epithelial cells have been reported but are not routinely used in the UK. These include nasopharyngeal and throat swabs, ${ }^{1-3}$ nasal washing with a rubber aspiration bulb, 4 nasal brushing with a cytology brush, ${ }^{5}$ and nasal curettage. ${ }^{6}$ We compared the technique of simple nasal lavage with that of standard nasopharyngeal aspiration for diagnosing RSV infection.

Paediatrics, Northwick

Park Hospital and Clinical Research Centre, Harrow, Middlesex

I M Balfour-Lynn

Department of Virology, St Bartholomew's Hospital, London D R Girdhar

Aitken

Correspondence to: Dr I M Balfour-Lynn, Drim Balfour-Lynn, Ormond Street Hospital for Children NHS Trust, Great Ormond Street, London WCIN $3 \mathrm{JH}$.

Accepted 6 October 1994 some of these were follow up samples when the children were symptom free. The subject was held in a supine position. Nasal lavage consisted of gently instilling $2 \mathrm{ml}$ of phosphate buffered saline, at room temperature, into each nostril. This was simultaneously suctioned back using a soft rubber 8 or 10 FG Jaques catheter (TFX Medical) from the anterior nares. The catheter was attached to a standard mucus extractor (Universal Hospital Supplies) connected to wall suction. Nasopharyngeal aspiration was conducted using the standard technique. An 8 FG PVC catheter was pushed to the back of the nasopharynx and the aspirate collected into a mucus trap. Each procedure took only a few minutes and adverse effects were not encountered with either technique, although some samples from nasopharyngeal aspiration were mildly bloodstained.

Nasal lavage fluid was centrifuged at $3000 \times g$ for 20 minutes. The catheter used for nasopharyngeal aspiration was rinsed first with $1 \mathrm{ml}$ viral transport medium before this mixture was centrifuged at $1500 \times g$ for 10 minutes. The supernatant was decanted and the pellet resuspended in sterile phosphate buffered saline. The washing procedure was repeated twice then the pellet was resuspended in $0.4 \mathrm{ml}$ sterile phosphate buffered saline.

The pellets contained intact epithelial cells; only $80 \%$ of cells obtained by lavage were intact compared with almost $100 \%$ from nasopharyngeal aspiration, but this was because the lavage samples had been frozen before analysis and would not be expected in fresh samples. Direct immunofluorescence for RSV and influenza $A$ antigens was carried out on the epithelial cells using commercial assays (Imagen, Dako Ltd) following the manufacturer's instructions. Influenza A was used as a control to detect non-specific fluorescence.

\section{Results}

Samples obtained by both techniques had a similar cellular composition, although nasal lavage gave a better cell yield.

There were $24 \mathrm{RSV}$ positive and $26 \mathrm{RSV}$ negative samples from nasopharyngeal aspiration. Taking nasopharyngeal aspiration as gold standard, nasal lavage gave one false positive and two false negative results (table). This means nasal lavage has $96.2 \%$ specificity (with $95 \%$ confidence interval (CI) $80 \cdot 0$ to $99 \cdot 9 \%$ )

Comparison of RSV detection in samples obtained by both techniques

\begin{tabular}{lrrr}
\hline & & \multicolumn{3}{c}{ Nasopharyngeal } \\
& & + & aspiration \\
Nasal & + & 22 & - \\
lavage & - & 2 & 25 \\
\hline
\end{tabular}


and $91 \cdot 7 \%$ sensitivity (CI 73.0 to $98.9 \%$ ). Nasal lavage had a positive predictive value of $95.6 \%$ (CI 78.0 to $99.9 \%$ ), and negative predictive value of $92 \cdot 5 \%$ (CI $75 \cdot 7$ to $99 \cdot 0 \%$ ).

\section{Discussion}

These results show that nasal lavage gives comparable results to the clinical gold standard of nasopharyngeal aspiration for diagnosing RSV infection. The one 'false positive' result could be discounted as it is more likely that the virus was simply not detected in the aspirate, rather than falsely detected in the lavage fluid. False negatives are more important in the context of this study and the negative predictive value was sufficiently high.

The main advantage of nasal lavage, however, is that it is free of the well documented adverse effects of nasopharyngeal aspiration (including vagal bradycardia and transient hypoxaemia). This is particularly important when specimens are being collected from sick infants with bronchiolitis. There is minimal risk of the lavage fluid being aspirated by the child as it is simultaneously suctioned back. Lavage also causes less discomfort to the children as the catheter need only be placed just inside the nose; this is of particular advantage in older children, especially if specimens are being taken for research purposes. Nasal lavage also has the advantage of clearing out mucus from the nose which eases breathing in some of the infants. Finally, lavage gives a better cell yield for analysis and does not result in specimens that require repeating due to an inadequate sample.

For these reasons, we would recommend this simple technique as a method of collecting respiratory epithelial cells for diagnosing RSV infection.

We would like to thank the children and their parents for participating in the study. This work was supported by a grant
from Allen and Hanburys Ltd, the Robert McAlpine Foundation, and The Samuel Scott of Yews Trust.

1 Treuhaft MW, Soukup JM, Sullivan BJ. Practical recommendations for the detection of pediatric respiratory syncytial virus infections. F Clin Microbiol 1985; 22: 270-3.

2 Ahluwalia G, Embree J, McNicol P, Law B, Hammond GW. Comparison of nasopharyngeal aspirate and nasopharyngeal swab specimens for respiratory syncytial virus diag nosis by cell culture, indirect immunofluorescence assay, and enzyme-linked immunosorbent assay. 7 Clin Microbiol 1987; 25: 763-7.

3 Mackie PLK, Madge PJ, Getty S, Paton JY, Rapid diagnosis of respiratory syncytial virus infection by using pernasal of respiratory syncytial virus infection by

4 Hall CB, Douglas RG. Clinically useful method for the isolation of respiratory syncytial virus. F Infect Dis 1975; 131: 1-5.

5 Barnes SD, Leclair JM, Forman MS, Townsend TR, Barnes SD, Leclair JM, Forman MS, Townsend TR,
Laughlin GM, Charache P. Comparison of nasal brush and nasopharyngeal aspirate techniques in obtaining specimens for detection of respiratory syncytial viral antigen by immunofluorescence. Pediatr Infect Dis $\mathcal{F} 1989$ 8: 598-601.

6 Jalowayski AA, Walpita P, Puryear BA, Connor JD. Rapid detection of respiratory syncytial virus in nasopharyngeal specimens obtained with the Rhinoprobe scraper. $f$ Clin Microbiol 1990; 28: 738-41. 